\title{
Job rotation and human-robot collaboration for enhancing ergonomics in assembly lines by a genetic algorithm
}

\author{
Michela Dalle Mura ${ }^{1}$ D $\cdot$ Gino Dini ${ }^{1}$
}

Received: 27 April 2021 / Accepted: 13 September 2021 / Published online: 6 October 2021

(c) The Author(s) 2021, corrected publication 2022

\begin{abstract}
Currently, the largest percentage of the employed workforce in the manufacturing industry is involved in the assembly process, making ergonomics a key factor when dealing with assembly-related problems. During these processes, repetitive tasks and heavy component handling are frequent for workers, who may result overloaded from an energetic point of view, thus affecting several aspects not only relating to the human factor but also to potentially reduced productivity. Different organizational strategies and technological solutions could be adopted to overcome these drawbacks. For these purposes, the present paper proposes a genetic algorithm for solving the typical problem of assembly line balancing, taking into account job rotation and human-robot collaboration for enhancing ergonomics of workers. The objectives of the problem are related to both economic aspects and human factor: (i) the cost for implementing the assembly line is minimized, evaluated on the basis of the number of workers and differentiated by skill levels and on equipment installed on workstations, including collaborative robots, and (ii) the energy load variance among workers is also minimized, so as to smooth their energy expenditure in performing the assigned assembly operations, calculated according to their movements, physiological characteristics, job rotations and degree of collaboration with robots. The paper finally presents and discusses the application of the developed tool to an industrial assembly case.
\end{abstract}

Keywords Assembly line balancing $\cdot$ Ergonomics $\cdot$ Job rotation $\cdot$ Human-robot collaboration $\cdot$ Genetic algorithm

\section{Introduction}

The human factor is becoming ever more central in industrial production systems. According to the 2030 Agenda for Sustainable Development [1], a specific goal is to promote safe and secure working environments for all workers, thus making ergonomics a key factor nowadays in the design of workplaces to ensure workers' well-being [2-4]. Motivations rely not only on safeguarding health and safety of personnel but also on economic aspects related to medical costs caused by physical and psychological damage and potential absenteeism, for which workers need to be replaced by unexperienced substitutes who may reduce productivity [5-7].

Michela Dalle Mura

m.dallemura@ing.unipi.it

Gino Dini

g.dini@ing.unipi.it

1 Department of Civil and Industrial Engineering, University of Pisa, 56122 Largo LazzarinoPisa, Italy
Among different processes, assembly currently involves the largest percentage of the employed workforce in the manufacturing industry, as most of the operations are manual. During assembly, repetitive movements and heavy components handling are frequent for workers, who may result physically stressed and overloaded from an energetic point of view $[8,9]$.

Based on these arguments, it can be stated that the design of assembly lines should undergo ergonomic considerations, on which the process efficiency highly depends $[8,10]$. The simple assembly line balancing problem of type 1 (SALBP1 ), whose main objective is to assign the operations necessary to assemble a mass product to the minimum number of workstations of a production line for a given cycle time, is one of the major problems to be solved in the field of assembly line design. Reasons rely on the mathematical combinatorial complexity of balancing, which is a NP-hard optimization problem, and on the great impact on economic factors its resolution has $[11,12]$.

To foster an ergonomic planning of assembly lines, different organizational strategies and technological solutions 
could be implemented, also taking into consideration personal features and physiological characteristics, such as gender and age, which differentiate each worker's physical capabilities [5].

\subsection{State of the art and motivations of the work}

In the scientific literature, different studies investigate ergonomics in assembly systems, mainly with the objective of reducing the ergonomic risk in terms of worker posture [13]. As an example, in [14], the design of assembly systems is aimed at improving ergonomics by avoiding work-related musculoskeletal disorders, potentially generated from certain tasks entailing frequent uncomfortable movements and positions. The outcome of the study highlights how productivity improvements can be reached with ergonomic improvements on assembly workstations. Other works develop digital tools for simulating the assembly process and for the design of system layouts to deal with ergonomics of workers [10, 15-18]. Among the solutions proposed for enhancing ergonomics, the implementation of job rotation strategies in assembly systems proved to effectively balance workload distribution among operators and reduce assembly errors [13, 19-23].

In the last years, several studies have been conducted to introduce the ergonomic risk also in the assembly line balancing problem [13]. In [24], different clusters of SALBP-1, named ErgoSALBP, are modelled to include the ergonomic risk into the assembly line balancing. The posture of the worker is evaluated in the work proposed in [25], through postural risk assessment techniques, with the objective of maximizing the physical workload balance and minimizing the accumulated risk of postures (ARPs), which evaluates the load on back, arms and legs. Studies presented in [26] propose a new objective function to minimize the maximum ergonomic risk on the line. The work developed in [27] deals with the optimization of traditional objectives for line balancing, i.e. the number of workstations and the workload variance, and of the ergonomic risk at each station, based on rapid upper limb assessment technique, which evaluates the strain of upper limbs, neck and torso. Also in other works $[28,29]$, the ergonomic risk is minimized, together with assembly process times. The study conducted in [30] considers a line balancing problem with ergonomic constraints for the minimization of the number of workers. Mokhtarzadeh et al. [31] propose a two-stage framework to first classify the risk of each task using various standards, such as the National Institute for Occupational Safety and Health (NIOSH), Occupational Repetitive Actions (OCRA) and Ergonomic Assessment Worksheet (EAWS), to then smooth the tasks of each class assigned to each workstation. In [32], the problem objectives are balancing the cycle time and the physical workload of operations among stations, evaluated through rapid entire body assessment (REBA) method. Ergonomic risk factors are also considered in the balancing problem faced in other works employing OCRA assessment technique [33, 34].

A different approach for considering ergonomics in the line balancing problem, mainly based on the assignment of assembly operations to workstations, is modelled in [35], where a time smoothness index and an energy smoothness index are optimized for SALBP-2 (in which the cycle time is minimized for a given number of workstations). In this case, ergonomic evaluations are based on energy expenditure of workers in carrying out assembly operations. The energy smoothness index is used to distribute the energetic workload among the different stations of the assembly line, disregarding however personal features of assigned workers, which can influence their physical capabilities. The ergonomic approach based on energy expenditure of workers has then been treated in other works concerning line balancing, such as [36].

In the academic research relating to assembly, different studies have also been carried out on human-robot collaboration (HRC) [37], the implementation of which could lead to advantages for workers' ergonomics. As a matter of fact, collaborative solutions for assembly lines could enhance not only process efficiency and flexibility, by combining human dexterity and cognitive capabilities with robot repetitiveness, but also reduce workers' physical effort, thanks to the robot support in heavy component handling [38-42]. Some assembly line balancing studies developed in the field propose the optimization of cost-related $[43,44]$ and time-related aspects $[45,46]$, while few others include ergonomic considerations $[47,48]$.

Table 1 summarizes the contributions characterizing cited references, showing, among others, if the work deals with assembly line balancing (ALB) or with a different approach concerning assembly, such as analysis or system design, job scheduling or process planning.

As resulting from Table 1, in the scientific literature relating the complex formulation of assembly line balancing, job rotation and HRC are never treated simultaneously, although both currently contribute to a sustainable development of assembly processes. The two aspects are of fundamental importance to allow a balanced distribution of the workload on operators, aimed at safeguarding them, protecting their health, welfare and safety.

For these reasons, the present work aims at facing the previous gap by proposing a software tool based on a novel genetic algorithm (GA) to solve a multi-objective version of the SALBP-1 for collaborative assembly lines including job rotation. The objectives of the problem are related to both economic aspects and human factor. In particular, the cost for implementing the assembly line is minimized, evaluated on the basis of the number of workers and differentiated by 
Table 1 Summary of contributions analysed in the literature

\begin{tabular}{|c|c|c|c|c|}
\hline References & ALB & Ergonomics & Job rotation & $\mathrm{HRC}$ \\
\hline 14 & Design & $\checkmark$ & & \\
\hline 15 & Analysis & $\checkmark$ & & \\
\hline 16 & Analysis & $\checkmark$ & & \\
\hline 10 & Analysis/design & $\checkmark$ & & \\
\hline 18 & Analysis & $\checkmark$ & & \\
\hline 19 & Design & $\checkmark$ & & \\
\hline 20 & Scheduling & $\checkmark$ & $\checkmark$ & \\
\hline 21 & Scheduling & $\checkmark$ & $\checkmark$ & \\
\hline 22 & ALB & $\checkmark$ & $\checkmark$ & \\
\hline 23 & Scheduling & $\checkmark$ & $\checkmark$ & \\
\hline 24 & Scheduling & $\checkmark$ & $\checkmark$ & \\
\hline 25 & ALB & $\checkmark$ & & \\
\hline 26 & ALB & $\checkmark$ & & \\
\hline 27 & ALB & $\checkmark$ & & \\
\hline 28 & ALB & $\checkmark$ & & \\
\hline 29 & ALB & $\checkmark$ & & \\
\hline 30 & ALB & $\checkmark$ & & \\
\hline 31 & ALB & $\checkmark$ & & \\
\hline 32 & ALB & $\checkmark$ & & \\
\hline 33 & ALB & $\checkmark$ & & \\
\hline 34 & ALB & $\checkmark$ & & \\
\hline 35 & ALB & $\checkmark$ & & \\
\hline 36 & ALB & $\checkmark$ & & \\
\hline 37 & ALB & $\checkmark$ & & \\
\hline 39 & Planning & & & $\checkmark$ \\
\hline 40 & Design & $\checkmark$ & & $\checkmark$ \\
\hline 41 & Design & $\checkmark$ & & $\checkmark$ \\
\hline 44 & ALB & & & $\checkmark$ \\
\hline 45 & ALB & & & $\checkmark$ \\
\hline 46 & ALB & & & $\checkmark$ \\
\hline 47 & ALB & & & $\checkmark$ \\
\hline 48 & ALB & $\checkmark$ & & $\checkmark$ \\
\hline 49 & ALB & $\checkmark$ & & $\checkmark$ \\
\hline
\end{tabular}

technical skill levels, and of equipment installed on workstations, including collaborative robots. The other objective to be minimized is the energy load variance among workers, so as to smooth their energy expenditure in performing the assigned assembly operations and not to exceed their physical capabilities. Energy expenditure parameter is calculated according to the movements in executing assembly tasks, to personal characteristics that differentiate each worker and to the degree of collaboration with robots.

\subsection{Proposed approach}

In the present study, assembly line workers are subject to a job rotation, an organizational strategy to periodically move workers among line stations, thus enabling different advantages for them, such as multi-tasking skills, reduction of monotony and improvement of ergonomics. Among various strategies analysed from both academic and industrial applications, a Ban rotation has been implemented, meaning that all workers can be assigned to all workstations [49]. To contrast the repetitiveness of movements, at each rotation, every worker is placed on a different workstation from the one of the previous rotation, given that a maximum of one worker can be assigned to each station. As regards the duration, the rotation of workers every $2 \mathrm{~h}$ on an 8 -h shift is employed, as it is appointed as the most efficient strategy from various applications for assembly lines [50, 51]. Furthermore, workers are characterized by different technical skills, which are intended in the present approach to range from a low to an intermediate until a high skill level. Workers can thus be assigned to workstations in which operations they are able to perform are allocated, so requiring a lower or equal skill level.

HRC has also been implemented for reducing workers physical effort by employing collaborative robots for burdensome operations. A workplace and time sharing system is considered, where human worker and collaborative robot are working in the same workplace and collaborating for assembly tasks [52]. Operations are characterized by the possibility to be performed manually and/or automatically and/or jointly by the human worker and the collaborative robot [53]. Given this, line stations can be (i) manual, if the assigned assembly tasks are performed by a worker; (ii) automatic, if tasks are performed by a robot; and (iii) collaborative, if tasks require workers and robots, working jointly or independently. Once assigned, robots are fixed and do not undergo any modification or rotation along the line. Moreover, automatic workstations, in which tasks are entirely executed by robots, are not considered for assigning workers during job rotation.

As an ergonomic factor, the present paper deals with the energy expenditure parameter, which is a measure of the worker's physical fatigue in performing manual operations. The energy expenditure evaluation is based on different aspects. In particular, it depends on personal characteristics and physiological parameters of workers, such as gender, age and weight, on body movements for completing manual tasks and on the eventual support of the robot in reducing the worker's physical load. The energy expenditure of workers is then compared to their energetic limits, again calculated according to personal characteristics, so as to ensure that no worker is physically overloaded or operating beyond capabilities.

Lastly, among the various resolution techniques for the problem proposed in the years, the software tool uses a GA to solve the SALBP-1, for the proven efficiency in reaching optimal solutions for complex and multiple constraint optimization problems [54]. 


\subsubsection{Problem modelling}

This section presents the problem formulation for the proposed multi-objective version of the SALBP-1.

The notations considered in the mathematical model for indices are defined as follows:

$k$ movement

$i, j$ operation

$z \quad$ worker

$w$ workstation

$q$ equipment

$r$ rotation

The parameters of the problem are:

$l_{k} \quad$ load to be moved in movement $k(\mathrm{~kg})$

$d l_{k} \quad$ distance $d l_{k}$ from the ground as starting point for vertical lifting and arrival point for vertical lowering during movement $k(\mathrm{~m})$

$d 2_{k} \quad$ distance $d 2_{n}$ from the ground as arrival point for vertical lifting and starting point for vertical lowering during movement $k(\mathrm{~m})$

$g \% \quad$ grade of the walking surface during movement $k$.

$k \quad$ speed of walking during movement $k(\mathrm{~m} / \mathrm{s})$

$h_{k} \quad$ horizontal movement of the arms in movement $k(\mathrm{~m})$

$N \quad$ number of assembly operations

$P_{i, j} \quad$ precedence between operation $i$ and operation $j$

$E Q_{i, q} \quad$ equipment $q$ required for operation $i$

$G_{z} \quad$ gender of worker $z$

$A z \quad$ age of worker $z$ (years)

$W_{z} \quad$ weight of worker $z(\mathrm{~kg})$

$H_{z} \quad$ height of worker $z(\mathrm{~m})$

$S_{z} \quad$ technical skill level of worker $z$

$E L_{z} \quad$ energetic limit of worker $z$ (kcal)

$n z \quad$ number of workers

$T \quad$ cycle time (min)

Parameters associated with each movement are present when applicable, based on the type of movement (e.g. lifting or lowering an object, walking).

As far as assembly operations are concerned, precedence constraints are contained in a binary square matrix, in which

$P_{i, j}=\left\{\begin{array}{l}1 \text { if operation } i \text { precedes operation } j ; \\ 0 \text { otherwise }\end{array}\right.$

Equipment include tools, automatic screwdrivers, pressing machines, vibratory feeders and collaborative robots necessary to accomplish assembly operations. These data are coded by an equipment matrix, where each element $E Q_{i, q}$ can be
$E Q_{i, q}=\left\{\begin{array}{l}1 \text { if operation } i \text { requires equipment } j ; \\ 0 \text { otherwise }\end{array}\right.$

As regards workers, gender is binary coded; in particular

$G_{z}=\left\{\begin{array}{l}1 \text { if worker } z \text { is a man; } \\ 0 \text { if worker } z \text { is a woman. }\end{array}\right.$

Technical skill level $S_{z}$ are coded as follows:

$S_{z}=\left\{\begin{array}{l}1 \text { if worker } z \text { has a low skill level; } \\ 2 \text { if worker } z \text { has an intermediate skill level; } \\ 3 \text { if worker } z \text { has a high skill level. }\end{array}\right.$

The energetic limit, evaluated to verify that no worker is operating beyond physical capabilities, is calculated as a function of the maximum power of a worker $\max W_{z}(\mathrm{~W})$, according to the calculations for professional applications proposed in [55]. Specifically, the energetic limit $E L_{z}$ (kcal) of worker $z$ is evaluated for a work shift of $8 \mathrm{~h}$ proportional to the $35 \%$ of $\max W_{z}$ :

$E L_{z}=0.06 \bullet 0.35 \cdot \max W_{z} \bullet T$

where $T(\mathrm{~min})$ is the cycle time and 0.06 is a conversion factor of units of measure. $\max W_{z}$ depends on maximum oxygen consumption $\mathrm{O} 2_{z}(1 / \mathrm{min})$, one of the most used physical condition index. The energy equivalent of oxygen at maximum exercise is $21.25 \mathrm{~kJ} / \mathrm{l}$. Thus, properly converting this value into consistent units, $\max W_{z}$, can be calculated as [55]:

$\max W_{z}=354.3 \cdot O 2_{z}$

The maximum oxygen consumption of workers depends on their peculiar characteristics and is calculated as proposed in [56, 57]:

$\mathrm{O} 2_{z}=\left\{\begin{array}{l}66.734-0.4 A_{z}-0.678\left(1.61 W_{z}^{2} / H_{z}-26\right) \\ \text { if worker } z \text { is a man } \\ 58.904-0.42 A_{z}-0.494\left(1.61 W_{z}^{2} / H_{z}-13.9\right) \\ \text { if worker } z \text { is a woman }\end{array}\right.$

Variables of the problem, whose value depends on the assignment resulting by the solution, are evaluated as follows.

Execution times can assume from 1 to 3 values, according to the possibility of performing movements and operations manually and/or automatically and/or collaboratively. For manual execution, time $T_{i}(\mathrm{~min})$ of operation $i$ is given by the sum of times $t_{k}(\mathrm{~min})$ of the various movements $k$ that the worker performs during operation $i$. For automatic execution, $T_{i}$ is equal to the time for the robot to perform operation $i$. For collaborative execution, $T_{i}(\mathrm{~min})$ is given by the sum of times $t_{k}(\mathrm{~min})$ of the various manual 
movements $k$ that the worker performs during operation $i$, plus the time for performing collaborative movements.

Skill level can assume different values as well, varying based on the manual and/or collaborative execution. In particular, $S L_{i}$ identifies the level of technical ability the worker must have at least to carry out operation $i$, codified as follows:

$S L_{i}=\left\{\begin{array}{l}1 \text { if operation } i \text { requires a low skill; } \\ 2 \text { if operation } i \text { requires an intermediate skill; } \\ 3 \text { if operation } i \text { requires a high skill. }\end{array}\right.$

The energy expenditure of workers is evaluated according to the calculations proposed by Garg [58]. The Garg model relates energy expenditure to the operator's oxygen consumption in executing the various movements that compose each manual operation. Once energy expenditure of movements is calculated for each assembly operation, the total energy expenditure $E_{z}$ (kcal) of worker $z$ can be evaluated. $E_{z}(\mathrm{kcal})$ is given as the sum of the energy expenditure $E_{z^{\prime} w}(\mathrm{kcal})$ of the various movements manually performed that compose assembly operations allocated to workstation $w$ where worker $z$ is placed, plus the energy at rest for maintaining the position till the end of cycle time:

$E_{z}=E_{z, w}+\dot{E} 0_{z} \cdot I T_{w}$

with

$E_{z, w}=\sum \sum_{k=1}^{n m_{i}} e_{k, i, z}$

where $e_{k, i, z}$ is the energy expenditure for movement $k$ of operation $i$ allocated to workstation $w$ where worker $z$ is placed. $\dot{E} \mathrm{O}_{z}(\mathrm{kcal} / \mathrm{min})$ is the energy expenditure rate for maintaining the position over time, calculated as a function of the worker's weight $W_{z}(\mathrm{~kg})$ and of the working position, as viewable in [58], while $I T_{w}$ is the idle time of workstation $w$ ( $\left.\mathrm{min}\right)$.

As regards the objective function $F$, the SALBP-1 version the present work deals with is to assign assembly operations to workstations in order to minimize the cost for implementing the assembly line and the energy load variance among workers. To this purpose, the following expression has been formulated:

$\min F=(\bar{C} \cdot \alpha+\bar{\sigma} \cdot(1-\alpha)) p$,

$\bar{C}$ and $\tilde{\sigma}$ are the values of the cost of the line $C$ and of the energy load variance $\sigma$ properly normalized between their lower and upper bounds, evaluated through simulations and empirical considerations; $\alpha$ and ( $1-\alpha)$ are the relative weight of objectives; $p$ is a penalty value related to the satisfaction of problem constraints, equal to $p= \begin{cases}0.50 & \text { if more than } 5 \text { constraints are not respected } \\ 0.65 & \text { if } 3 \text { or } 4 \text { constraints are not respected } \\ 0.80 & \text { if } 1 \text { or } 2 \text { constraints are not respected } \\ 1 & \text { otherwise }\end{cases}$

The first objective to be minimized is the cost $C(€ / \mathrm{h})$ for implementing the assembly line, given by

$C=\sum_{w=1}^{n w}\left(C_{z, w}+\sum_{q=1}^{n q} C_{q, w}\right)$,

being $n w$ is the number of workstations established by allocating the operations into workstations such that the sum of execution times does not exceed the cycle time; $C_{z, w}$ $(€ / \mathrm{h})$ is the hourly cost of worker $z$ placed in workstation $w$ that range from 0 if no worker is present and then growing with technical skill level growing; $n q$ is the number of equipment units allocated to workstation $w$; and $C_{q, w}$ $(€ / \mathrm{h})$ is the hourly cost of the equipment $q$ at workstation $w$. This formulation of the cost objective allows not only avoiding duplication of resources, but also minimizing the number of workstations, consistently with SALBP-1 formulation.

The other objective to be minimized is the energy load variance $\sigma$ among workers, given by

$\sigma=\sqrt{\frac{\sum_{z=1}^{n z}\left(\overline{\Delta E}-\Delta E_{z}\right)^{2}}{n w}}$,

where $n z$ is the number of workers and $\overline{\Delta E}$ is the mean energy gap among workers, being $\Delta E_{z}$ the normalized value of energy gap between the physical limit of worker $z$ and the energy expenditure for performing the assembly operations. Given the implemented job rotation, each worker in an 8-h shift is assigned to 4 workstations (one every $2 \mathrm{~h}$ ) where different assembly operations are allocated, thus requiring different energy expenditure at each rotation. Therefore, $\Delta E_{z}$ is obtained as follows:

$\Delta E_{z}=\sum_{r=1}^{4} \frac{\Delta E_{z, r}}{4}$,

with $\Delta E_{z, r}$ is normalized value of energy gap between the physical limit of worker $z$ and the energy expenditure during rotation $r$, calculated for each rotation as

$\Delta E_{z, r}=1-\frac{E_{z}}{E L_{z}}$.

The problem is subject to various constraints that, besides traditional ones on cycle time and precedence relationships to be respected, have been specifically introduced to deal with this specific version of SALBP-1. In particular, for each worker $z$ at each job rotation $r$ : 
- The energy expenditure must not exceed the energetic limit:

$E_{z} \leq E L_{z}$

- The maximum power $\max W_{z}$, must not be exceeded:

$\max \left\{W_{i, z}\right\} \leq \max W_{z}$

being $W_{i, z}(\mathrm{~W})$ the power required to perform operation $i$ for worker $z$.

- The technical skill level $S_{z}$, must be equal or higher than the maximum one $\max S L_{w}$ required to carry out assembly operations at workstation $w$ where worker $z$ is placed:

$\max S L_{w} \leq S_{z}$.

- The workstation $w_{z, r}$ where worker $z$ is placed during rotation $r$ must be different from the one occupied at the previous rotation $w_{z, r-1}$ :

$w_{z, r} \neq w_{z, r-1}$.

\subsubsection{Genetic algorithm architecture}

The software tool based on the use of a GA for the resolution of the modelled problem has been developed on MATLAB®.

The chromosome structure for the proposed GA is based on a tailored encoding method for the particular problem that uses the task-oriented representation for the assembly sequence. With each task-oriented chromosome, generated by a sequence planner that ensures the respect of precedence constraints, two other elements are randomly created and associated: a string named equipment-oriented chromosome with a number of elements equal to the number of workstations $(n w)$ containing the necessary equipment for each station, including collaborative robots, and a matrix named job rotation-oriented chromosome of dimensions $4 \mathrm{x} n w$ with information on job rotation.

An example of chromosome, structured as proposed, is shown in Fig. 1. The task-oriented chromosome is composed of 10 genes encoding 10 assembly operations placed in order of execution. The same figure also shows the equipment-oriented chromosome with equipment ( $S$ for automatic screwdriver, $P$ for pressing machine, $V 1$ for vibratory feeder for screws, $V 2$ for vibratory feeder for nuts) and robots $(R)$ assigned to the 5 workstations of the line $(n w=5)$, distinct by different colours. In the underlying job rotation-oriented chromosome, for each of the 4 rotations, the sequence of workers, among the ones available in a company, is reported. As examples, in the first workstation, in yellow, assembly operations 3 and 2 are allocated and need to be manually performed with the use of a screwdriver $(S)$ and vibratory feeder for screws $(V I)$ by worker $A$ at the first rotation, $C$ at the second, $D$ at the third and so on. In the second workstation,

\begin{tabular}{|c|c|c|c|c|c|c|c|c|c|c|}
\hline $\begin{array}{c}\text { Task-oriented } \\
\text { chromosome }\end{array}$ & 3 & 2 & 4 & 5 & 1 & 6 & 9 & 7 & 8 & 10 \\
\hline $\begin{array}{c}\text { Equipment-oriented } \\
\text { chromosome }\end{array}$ & $\mathrm{S}-\mathrm{V} 1$ & $\mathrm{R}$ & \multicolumn{2}{|c|}{$\mathrm{R}-\mathrm{P}-\mathrm{V} 2$} & $\mathrm{~S}-\mathrm{V} 1$ & $\mathrm{R}-\mathrm{V} 2$ \\
\hline \multirow{2}{*}{$\begin{array}{c}\text { Job rotation-oriented } \\
\text { chromosome }\end{array}$} & $\mathrm{A}$ & - & $\mathrm{C}$ & $\mathrm{D}$ & $\mathrm{B}$ \\
\cline { 2 - 7 } & $\mathrm{D}$ & - & $\mathrm{A}$ & $\mathrm{B}$ & $\mathrm{D}$ \\
\cline { 2 - 7 } & $\mathrm{C}$ & - & $\mathrm{B}$ & $\mathrm{C}$ & $\mathrm{A}$ \\
\hline
\end{tabular}

Fig. 1 Example of chromosome structure, divided in task-oriented chromosome with assembly sequence; equipment-oriented chromosome with equipment and robots in workstations; job rotationoriented chromosome with workers rotating among manual and collaborative stations

only operation 4 is automatically performed. Conversely, the third workstation is collaborative, and robot $(R)$ and worker (first $C$, then $A$ and so on) working together helped by pressing machine $(P)$ and vibratory feeder for nuts $(V 2)$.

To evaluate each chromosome, the objective function $F$ described by Eq. 11 is used as fitness function. The lower the value of $F$ is, the higher the probability is for the chromosome to survive to following generations of the GA.

Roulette wheel selection is applied at each iteration of the GA to select chromosomes for producing offspring, according to their fitness value. The order-based crossover is then employed to ensure feasible assembly sequences in terms of precedence constraints.

As shown in Fig. 2, this genetic operator is applied to the task-oriented chromosome by selecting a couple of parents, each of them randomly divided into initial, intermediate and final part; the two parents produce two children, each of them made by initial and final part of one parent and by missing genes ordered as they are in the other parent. Then, the swap mutation is used for exchanging two randomly selected genes in task-oriented chromosome. This genetic operator is exemplified in Fig. 3 and has been implemented to enable proper randomness in the algorithm, which could lead to improved solutions through generations. Equipment and job-oriented parts of the chromosome remain unchanged after genetic operations, so that the fitness function is eventually penalized if some constraints are violated. Strong elitism is then applied to only preserve chromosomes with outperforming fitness values, for enforcing a steady enhancement of solutions.

\section{Validation}

Different numerical examples and real case studies have been analysed for testing the software tool. In this paper, results for the assembly process of a product taken from the automotive industry are presented. In particular, the assembly of a vehicle front-end has been selected because they 


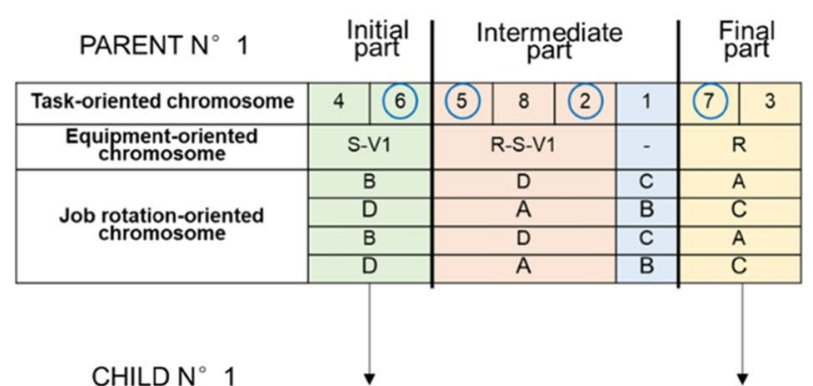

\begin{tabular}{|c|c|c|c|c|c|c|c|c|}
\hline Task-oriented chromosome & 4 & 6 & 1 & 5 & 2 & 8 & 7 & 3 \\
\hline $\begin{array}{c}\text { Equipment-oriented } \\
\text { chromosome }\end{array}$ & $\mathrm{S}-\mathrm{V} 1$ & $\mathrm{R}-\mathrm{S}-\mathrm{V} 1$ & - & $\mathrm{R}$ \\
\hline \multirow{3}{*}{$\begin{array}{c}\text { Job rotation-oriented } \\
\text { chromosome }\end{array}$} & $\mathrm{B}$ & $\mathrm{D}$ & $\mathrm{C}$ & $\mathrm{A}$ \\
\cline { 2 - 7 } & $\mathrm{D}$ & $\mathrm{A}$ & $\mathrm{B}$ & $\mathrm{C}$ \\
\cline { 2 - 7 } & $\mathrm{B}$ & $\mathrm{D}$ & $\mathrm{C}$ & $\mathrm{A}$ \\
\cline { 2 - 7 } & $\mathrm{D}$ & $\mathrm{A}$ & $\mathrm{B}$ & $\mathrm{C}$ \\
\hline
\end{tabular}

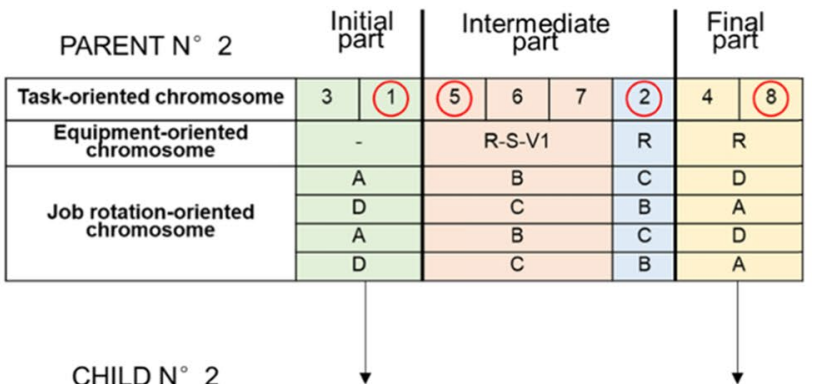

\begin{tabular}{|c|c|c|c|c|c|c|c|c|}
\hline Task-oriented chromosome & 3 & 1 & 6 & 5 & 2 & 7 & 4 & 8 \\
\hline $\begin{array}{c}\text { Equipment-oriented } \\
\text { chromosome }\end{array}$ & - & \multicolumn{2}{|c|}{ R-S-V1 } & R & R \\
\hline \multirow{3}{*}{\begin{tabular}{c}
\multirow{2}{*}{$\begin{array}{c}\text { Job rotation-oriented } \\
\text { chromosome }\end{array}$} \\
\cline { 2 - 7 }
\end{tabular}} & $\mathrm{A}$ & $\mathrm{D}$ & $\mathrm{B}$ & $\mathrm{C}$ & $\mathrm{C}$ & $\mathrm{D}$ \\
\cline { 2 - 7 } & $\mathrm{A}$ & \multicolumn{2}{|c|}{$\mathrm{B}$} & $\mathrm{C}$ & $\mathrm{D}$ \\
\cline { 2 - 7 } & $\mathrm{D}$ & \multicolumn{2}{|c|}{$\mathrm{C}$} & $\mathrm{B}$ & $\mathrm{A}$ \\
\hline
\end{tabular}

Fig. 2 Example of order-based crossover applied to task-oriented chromosome

\section{PARENT}

\begin{tabular}{|c|c|c|c|c|c|c|c|c|}
\hline Task-oriented chromosome & 4 & 6 & 1 & 5 & 2 & 8 & 7 & 3 \\
\hline $\begin{array}{c}\text { Equipment-oriented } \\
\text { chromosome }\end{array}$ & $\mathrm{S}-\mathrm{V} 1$ & \multicolumn{2}{|c|}{ R-S-V1 } & - & $\mathrm{R}$ \\
\hline \multirow{3}{*}{\begin{tabular}{c}
\multirow{2}{*}{$\begin{array}{c}\text { Job rotation-oriented } \\
\text { chromosome }\end{array}$} \\
\cline { 2 - 7 }
\end{tabular}} & $\mathrm{B}$ & $\mathrm{D}$ & $\mathrm{D}$ & $\mathrm{A}$ & $\mathrm{B}$ & $\mathrm{A}$ \\
\cline { 2 - 7 } & $\mathrm{B}$ & $\mathrm{D}$ & $\mathrm{C}$ & $\mathrm{C}$ \\
\cline { 2 - 6 } & $\mathrm{D}$ & $\mathrm{A}$ & $\mathrm{B}$ & $\mathrm{C}$ \\
\hline
\end{tabular}

CHILD

\begin{tabular}{|c|c|c|c|c|c|c|c|c|}
\hline Task-oriented chromosome & 4 & 7 & 1 & 5 & 2 & 8 & 6 & 3 \\
\hline $\begin{array}{c}\text { Equipment-oriented } \\
\text { chromosome }\end{array}$ & $\mathrm{S}-\mathrm{V} 1$ & \multicolumn{3}{|c|}{$\mathrm{R}-\mathrm{S}-\mathrm{V} 1$} & - & $\mathrm{R}$ \\
\hline \multirow{3}{*}{$\begin{array}{c}\text { Job rotation-oriented } \\
\text { chromosome }\end{array}$} & $\mathrm{B}$ & \multicolumn{2}{|c|}{$\mathrm{D}$} & $\mathrm{C}$ & $\mathrm{A}$ \\
\cline { 2 - 7 } & $\mathrm{D}$ & \multicolumn{2}{|c|}{$\mathrm{A}$} & $\mathrm{B}$ & $\mathrm{C}$ \\
\cline { 2 - 7 } & $\mathrm{B}$ & \multicolumn{2}{|c|}{$\mathrm{D}$} & $\mathrm{C}$ & $\mathrm{A}$ \\
\cline { 2 - 7 } & $\mathrm{D}$ & \multicolumn{2}{|c|}{$\mathrm{A}$} & $\mathrm{B}$ & $\mathrm{C}$ \\
\hline
\end{tabular}

Fig. 3 Example of swap mutation applied to task-oriented chromosome of the first child of Fig. 2

are representative in terms of both market diffusions, so as to justify the investment for a collaborative production line, and necessary equipment, especially robots for supporting workers in handling large components.

\subsection{Dataset}

The exploded view of the vehicle front-end is shown in Fig. 4. The assembly sequence for the 36 depicted components is formed by 29 operations. The assumptions for the problem include a production rate of 12 products/hour, a line efficiency of $96 \%$ and thus a cycle time of $4.80 \mathrm{~min} /$ product. The experiments have been conducted with a population size of 100 and a number of iterations of 150 . Crossover and mutation probability have been set to 0.98 and 0.1 , respectively, while 0.5 has been used as $\alpha$ value (Eq. 11) to prioritize both objectives during the optimization through the same weight.
Initial data for the problem are given in Table 2 as regards labour and equipment costs while in Table 3 as regards the assembly process. In particular, for each task, the following input are reported: precedence constraints; manual execution time; automatic execution time; collaborative execution time; required skill level for manual execution; required skill level for collaborative execution; and needed equipment (robots are optional). To calculate energy expenditure, movements have been identified for every assembly operation, reaching a total of 177 movements for the 29 operations. As an example, movements have been detailed for the manual execution of task n.10 in Table 4, where related energy expenditures are also calculated for two workers (I and R) selected from the group of available operators simulated for the validation, whose peculiar characteristics are shown in Table 5.

As stated before, energy expenditures are calculated according to the formulas reported by Garg in [58]. To provide a better understanding, let consider, as examples, movements 1 and 3 in Table 4, walking and lifting, respectively. The values of $e_{k, i, z}$ reported in the table are calculated as follows [58]:

For walking:

$e_{k, i, z}=10^{-2}\left(51+2.54 W_{z} s w_{k}^{2}+0.379 g \% s w_{k}^{2}\right) t_{k}$

For lifting:

$e_{k, i, z}=10^{-2}\left[0.062 W_{z}\left(d 2_{k}-0.81\right)+\left(3.19 l_{k}-0.52 G_{z} 1_{k}\right)\left(d 2_{k}-d 1_{k}\right)\right]$

\section{Results and discussion}

The optimal solution obtained with the developed algorithm using the dataset depicted in Sect. 4.1 is represented in Fig. 5, where the relative chromosome structure is shown. The solution resulted to be the one with the best fitness 
Fig. 4 Exploded view of the vehicle front-end used for software testing and presentation of results

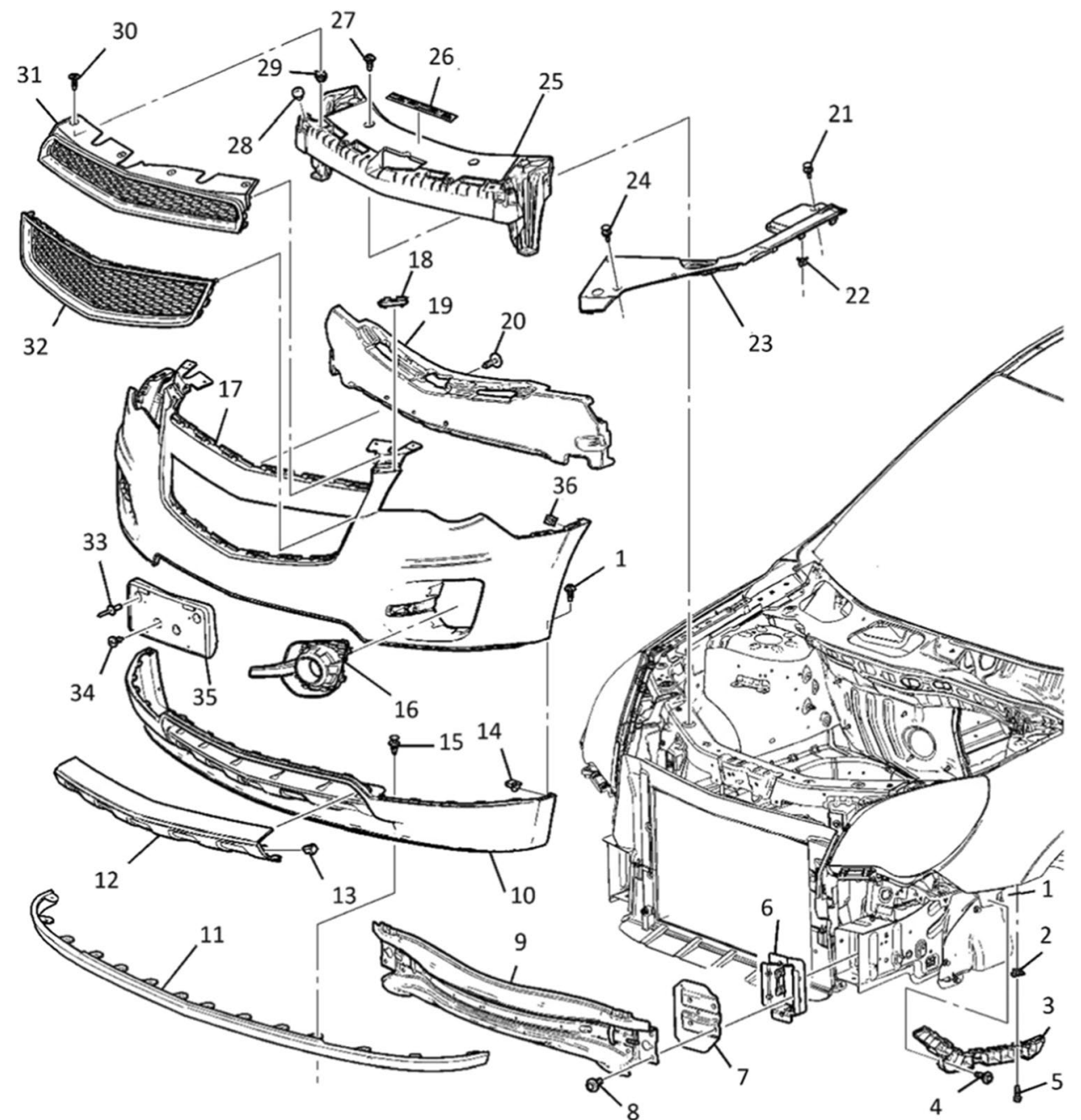

Table 2 Costs data of workers and equipment

\begin{tabular}{lll}
\hline \multirow{6}{*}{ Workers } & Resource & $\begin{array}{l}\text { Hourly } \\
\text { cost } C_{z} \\
(€ / \mathrm{h})\end{array}$ \\
\cline { 2 - 2 } Equipment & Worker with low skill level $\left(S_{z}=1\right)$ & 24.7 \\
& Worker with intermediate skill level $\left(S_{z}=2\right)$ & 28.7 \\
& Worker with high skill level $\left(S_{z}=3\right)$ & 32.7 \\
& Robot (R) & 14 \\
& Automatic screwdriver (S) & 6 \\
& Pressing machine (P) & 7 \\
& Vibratory feeder for screws (V1) & 10 \\
& Vibratory feeder for nuts (V2) & 10 \\
& Vibratory feeder for rivets (V3) & 10 \\
\hline
\end{tabular}

value, equal to 0.83 , very close to the maximum value of 1 , meaning that both objectives of the problem have been achieved. As viewable from Fig. 5, the chromosome returned by the proposed software tool provides an assembly line made of 6 workstations, differentiated by colours, and requiring 6 workers, selected from the group of Table 5.

The computed solution is also represented in Fig. 6 in terms of the energy load histogram for the 6 workers. In this graph, the height of bars corresponds to $\Delta E_{z}$, the mean energy expenditure of workers in carrying out the assigned operations during the 4 rotations, explained by Eq. 15. The same figure shows, below the graph, the values of the energy gap between the physical limit and the energy expenditure of every worker for each of the 4 rotations $\left(\Delta E_{z, r}\right.$ (Eq. 16)). Energy expenditure is reported in normalized value between 0 and 1 , to be comparable among workers.

To better clarify, in the fifth workstation of the line (the green one in Fig. 5), operations 23, 29, 24 and 26, presented in Table 3, are performed through the use of a robot (R) and a screwdriver (S) by the following workers selected from the group of Table 5: $\mathrm{W}$ at the first rotation, $\mathrm{O}$ at the second, $\mathrm{G}$ at the third and $U$ at the fourth. These workers are subject to different energy consumptions. As an example, the energy expenditure of worker U (the first column of Fig. 6) is 0.27 
Table 3 Initial data for the presented case study

\begin{tabular}{|c|c|c|c|c|c|c|c|}
\hline Task $i$ & Prec. $j$ & Manual $T_{i}(\min )$ & $\begin{array}{l}\text { Automatic } \\
T_{i} \text { (min) }\end{array}$ & $\operatorname{HRC} T_{i}(\min )$ & Manual $S L_{i}$ & HRC $S L_{i}$ & Equipment $q$ \\
\hline 1 & - & 0.58 & - & 0.50 & 3 & 3 & $\mathrm{R}, \mathrm{S}, \mathrm{V} 1, \mathrm{~V} 2$ \\
\hline 2 & - & 0.58 & - & 0.50 & 3 & 3 & $\mathrm{R}, \mathrm{S}, \mathrm{V} 1, \mathrm{~V} 2$ \\
\hline 3 & 1 & 0.44 & - & - & 2 & - & $\mathrm{S}, \mathrm{V} 1$ \\
\hline 4 & 2 & 0.44 & - & - & 2 & - & $\mathrm{S}, \mathrm{V} 1$ \\
\hline 5 & - & 0.58 & - & 0.51 & 2 & 1 & $\mathrm{R}, \mathrm{P}$ \\
\hline 6 & - & 0.58 & - & 0.51 & 2 & 1 & $\mathrm{R}, \mathrm{P}$ \\
\hline 7 & 5 & 0.54 & 0.45 & - & 3 & - & $\mathrm{R}$ \\
\hline 8 & 6 & 0.54 & 0.45 & - & 1 & - & $\mathrm{R}$ \\
\hline 9 & 7,8 & 2.22 & - & 2.10 & 3 & 2 & $\mathrm{R}, \mathrm{S}, \mathrm{V} 1$ \\
\hline 10 & - & 0.69 & - & 0.61 & 2 & 1 & $\mathrm{R}, \mathrm{P}$ \\
\hline 11 & - & 0.65 & 0.60 & - & 1 & - & $\mathrm{R}$ \\
\hline 12 & 11 & 0.38 & 0.35 & - & 1 & - & $\mathrm{R}$ \\
\hline 13 & 11 & 0.98 & 0.85 & - & 2 & - & $\mathrm{R}$ \\
\hline 14 & 11 & 0.98 & 0.85 & - & 2 & - & $\mathrm{R}$ \\
\hline 15 & 11 & 0.64 & - & - & 3 & - & $\mathrm{S}, \mathrm{V} 1$ \\
\hline 16 & 11 & 0.54 & - & - & 1 & - & - \\
\hline 17 & 14 & 0.64 & - & - & 3 & - & $\mathrm{V} 3$ \\
\hline 18 & 13 & 0.64 & - & - & 3 & - & V3 \\
\hline 19 & 13,14 & 0.94 & - & - & 1 & - & $\mathrm{S}, \mathrm{V} 1$ \\
\hline 20 & $3,4,9,10$ & 1.65 & 1.56 & 1.47 & 2 & 1 & $\mathrm{R}, \mathrm{V} 2$ \\
\hline 21 & 20 & 0.70 & - & 0.62 & 2 & 1 & $\mathrm{R}, \mathrm{S}, \mathrm{V} 1$ \\
\hline 22 & 20 & 1.20 & - & 1.14 & 2 & 1 & $\mathrm{R}, \mathrm{S}, \mathrm{V} 1, \mathrm{~V} 2$ \\
\hline 23 & 20 & 0.69 & 0.60 & - & 1 & - & $\mathrm{R}$ \\
\hline 24 & 20 & 1.42 & - & - & 2 & - & - \\
\hline 25 & 20,16 & 0.62 & - & 0.57 & 2 & 1 & $\mathrm{R}$ \\
\hline 26 & 25 & 0.90 & - & 0.81 & 2 & 1 & $\mathrm{R}, \mathrm{S}$ \\
\hline 27 & 22 & 0.87 & 0.79 & - & 2 & - & $\mathrm{R}$ \\
\hline 28 & 22 & 1.69 & - & - & 1 & - & V3 \\
\hline 29 & 27 & 1.43 & - & 1.35 & 2 & 1 & $\mathrm{R}, \mathrm{S}$ \\
\hline
\end{tabular}

Table 4 Example of movement decomposition referred to manual task n.10 of Table 3 related to the assembly of component n.19 in Fig. 4

\begin{tabular}{llllllllll}
\hline Description of movement & $t_{\mathrm{k}}(\mathrm{min})$ & $l_{\mathrm{k}}(\mathrm{kg})$ & $d 1_{\mathrm{k}}(\mathrm{m})$ & $d 2_{\mathrm{k}}(\mathrm{m})$ & $\mathrm{g}(\%)$ & $\mathrm{sw}_{\mathrm{k}}(\mathrm{m} / \mathrm{s})$ & $h_{\mathrm{k}}(\mathrm{m})$ & $e_{\mathrm{k}, 10, \mathrm{I}}(\mathrm{kcal})$ & $e_{\mathrm{k}, 10, \mathrm{R}}(\mathrm{kcal})$ \\
\hline 1 Walk to shelf & 0.07 & 0 & 0 & 0 & 1 & 1 & 0 & 0.209 & 0.177 \\
2 Forward movements of arms & 0.05 & 0 & 0 & 0 & 1 & 0 & 0.4 & 0.025 & 0.025 \\
3 Lift component n.19 & 0.06 & 5.7 & 1.0 & 1.45 & 1 & 0 & 0 & 0.115 & 0.096 \\
4 Carry component n.19 to workbench & 0.07 & 5.7 & 0 & 0 & 1 & 1 & 0 & 0.244 & 0.211 \\
5 Place component n.19 with press & 0.44 & 5.7 & 1.0 & 1.45 & 1 & 0 & 0 & 0.076 & 0.076 \\
\hline
\end{tabular}

at the first rotation, 0.41 at the second, 0.27 at the third and 0.36 at the fourth, producing a mean value of 0.33 that corresponds to the height of the bar.

As regards the first objective relating costs, the software shows to be able to assign to each workstation a worker having the exact skill level required by the allocated tasks, so as to minimize the number of high-skilled workers on the line and thus reduce costs. As an example, workers $\mathbf{J}$ an $\mathrm{L}$ are the only 2 , among the 6 workers selected, to have a high skill level $\left(S_{J}=S_{L}=3\right)$ and are alternatively placed on workstations 2 and 3, as viewable from Fig. 5, where the operations requiring a high skill level are performed, such as 1, 2, 17, 18 and 9, $15\left(S L_{1}=S L_{2}=S L_{9}=S L_{15}=S\right.$ $L_{17}=S L_{18}=3$ ). Similar considerations apply to equipment resources; the only operations requiring a pressing machine (i.e. 5, 6 and 10) are all executed in the first workstation, where a pressing machine will be placed; operations 3, 4, 9 and 15 to be performed with both a vibratory feeder for 
Table 5 Group of workers

\begin{tabular}{|c|c|c|c|c|c|}
\hline Worker $z$ & $\begin{array}{l}\text { Age } A_{z} \\
\text { (years) }\end{array}$ & $\begin{array}{l}\text { Weight } \\
W_{z}(\mathrm{~kg})\end{array}$ & $\begin{array}{l}\text { Height } \\
H_{z}(\mathrm{~m})\end{array}$ & Gender $G_{z}$ & Skill $S_{z}$ \\
\hline A & 42 & 80 & 1.71 & 1 & 1 \\
\hline B & 30 & 50 & 1.59 & 0 & 2 \\
\hline $\mathrm{C}$ & 30 & 85 & 1.78 & 1 & 1 \\
\hline $\mathrm{D}$ & 55 & 90 & 1.80 & 1 & 1 \\
\hline $\mathrm{E}$ & 26 & 60 & 1.72 & 0 & 2 \\
\hline $\mathrm{F}$ & 44 & 89 & 1.74 & 0 & 2 \\
\hline $\mathrm{G}$ & 40 & 79 & 1.65 & 1 & 2 \\
\hline $\mathrm{H}$ & 50 & 90 & 1.72 & 0 & 1 \\
\hline I & 59 & 85 & 1.80 & 0 & 2 \\
\hline $\mathrm{J}$ & 24 & 70 & 1.64 & 1 & 3 \\
\hline $\mathrm{K}$ & 30 & 75 & 1.82 & 1 & 1 \\
\hline $\mathrm{L}$ & 30 & 50 & 1.58 & 0 & 3 \\
\hline M & 30 & 85 & 1.77 & 1 & 1 \\
\hline $\mathrm{N}$ & 55 & 90 & 1.81 & 1 & 2 \\
\hline $\mathrm{O}$ & 40 & 75 & 1.70 & 1 & 2 \\
\hline $\mathrm{P}$ & 30 & 50 & 1.65 & 0 & 2 \\
\hline Q & 50 & 90 & 1.76 & 1 & 1 \\
\hline $\mathrm{R}$ & 23 & 69 & 1.57 & 1 & 2 \\
\hline $\mathrm{S}$ & 44 & 72 & 1.72 & 0 & 3 \\
\hline $\mathrm{T}$ & 44 & 89 & 1.74 & 0 & 2 \\
\hline $\mathrm{U}$ & 38 & 80 & 1.81 & 1 & 2 \\
\hline V & 41 & 75 & 1.78 & 0 & 1 \\
\hline W & 30 & 50 & 1.65 & 0 & 2 \\
\hline$X$ & 52 & 89 & 1.89 & 1 & 3 \\
\hline $\mathrm{Y}$ & 48 & 78 & 1.75 & 1 & 2 \\
\hline $\mathrm{Z}$ & 58 & 95 & 1.64 & 1 & 1 \\
\hline
\end{tabular}

screws and a screwdriver are all in the third workstation; in workstation 5, operations not requiring any vibratory feeder are grouped. The distribution of operations according to the required skill level and equipment avoids the duplication of resources among workstations and allows minimizing costs for the line implementation.

Relating to the other objective of energy load variance, in the proposed solution, the last workstation is completely manual, while the others entail HRC, as viewable from Fig. 5. As a matter of fact, $47 \%$ of operations in the proposed configuration require the support of a robot, highlighting the importance of collaborative work in manual assembly processes. Indeed, the strong presence of robots is reflected in data related to workers' energy expenditure. As shown in Fig. 6, the physical limit, given by the maximum energy expenditure value $(\Delta E=1)$, is always respected; furthermore, the use of collaborative robots allows a reduction in energy expenditure, which is largely below half of the energetic limit for all workers $\left(\Delta E_{z} \leq 0.4 \forall z\right)$ that are thus working beyond their physical capabilities. Also, Fig. 6 reports a well-balanced workload for operators, which are subject to similar energy expenditure during rotations, thus demonstrating to reduce the energy load variance.

The correct functioning of the software tool can also be deduced from Fig. 7, where a comparison on the energy load histogram of Fig. 6, obtained at the final iteration number 150 (in orange), with the one of solution found with the algorithm running, precisely at iteration 25 (in blue), is shown. Workers reported in Fig. 7 refer to the blue solution. The fitness value is in this case 0.48 , nearly half of the fitness of the best solution. As shown, the energetic workload is not well distributed among workers, which are almost all subject to higher energy expenditure. These types of assignments are discarded during the algorithm execution to prioritize and evolve towards improved solutions, as the one given in Fig. 6.

To better appreciate these results, the basic scenario described in Sect. 4.1 has been also used for some comparisons within the same proposed approach, given the novelty of the objectives introduced in this work. In particular, the solution obtained in Fig. 5 and represented in Fig. 6 has been compared with two different configurations, obtained maintaining the remaining conditions and re-executing the GA: in the first, workers are not subject to a job rotation but remain fixed in the assigned workstations; in the second, collaborative robots are not employed, so the entire assembly process is carried out manually. The configuration without job rotation is shown in Fig. 8 and can be noticed to produce a worst distribution of the energy load, if compared to Fig. 6, where job rotation is implemented. In fact, the system is still able not to violate energetic limits of workers, but the absence of job rotation clearly worsens workload smoothness among them. In the case of employing job rotation but not HRC, results are shown in Fig. 9. As viewable, if collaborative robots are not present, one worker and one workstation more are necessary on the line because some assembly operations (e.g. 1, 9, 20) may require longer times if manually performed, compared to a collaborative or automatic execution
Fig. 5 Chromosome structure for the best solution returned by the algorithm for product of Fig. 2

\begin{tabular}{|c|c|c|c|c|c|c|c|c|c|c|c|c|c|c|c|c|c|c|c|c|c|c|c|c|c|c|c|c|c|}
\hline $\begin{array}{l}\text { Task-oriented } \\
\text { chromosome }\end{array}$ & 11 & 16 & 10 & 5 & 13 & 12 & 6 & 8 & 14 & 1 & 17 & 19 & 18 & 2 & 7 & 15 & 9 & 4 & 3 & 20 & 22 & 25 & 27 & 21 & 23 & 29 & 24 & 26 & 28 \\
\hline $\begin{array}{l}\text { Equipment- } \\
\text { oriented } \\
\text { chromosome }\end{array}$ & \multicolumn{8}{|c|}{ R-P } & \multicolumn{7}{|c|}{ R-S-V1-V/2-V3 } & \multicolumn{4}{|c|}{ R-S-V1 } & \multicolumn{5}{|c|}{ R-S-V1-V2 } & \multicolumn{4}{|c|}{ R-S } & V3 \\
\hline \multirow{4}{*}{$\begin{array}{l}\text { Job rotation- } \\
\text { oriented - } \\
\text { chromosome }\end{array}$} & \multicolumn{8}{|c|}{ u } & \multicolumn{7}{|c|}{$\mathrm{J}$} & \multicolumn{4}{|c|}{ L } & \multicolumn{5}{|c|}{0} & \multicolumn{4}{|c|}{ w } & G \\
\hline & \multicolumn{8}{|c|}{$G$} & \multicolumn{7}{|c|}{$L$} & \multicolumn{4}{|c|}{$\mathrm{J}$} & \multicolumn{5}{|c|}{ W } & \multicolumn{4}{|c|}{0} & $u$ \\
\hline & \multirow{2}{*}{\multicolumn{8}{|c|}{ U }} & \multicolumn{7}{|c|}{$\mathrm{J}$} & \multicolumn{4}{|c|}{ L } & \multicolumn{5}{|c|}{0} & \multicolumn{4}{|c|}{ G } & W \\
\hline & & & \multicolumn{6}{|c|}{ G } & \multicolumn{7}{|c|}{$L$} & \multicolumn{4}{|c|}{ J } & \multicolumn{5}{|c|}{ W } & \multicolumn{4}{|c|}{$U$} & 0 \\
\hline
\end{tabular}




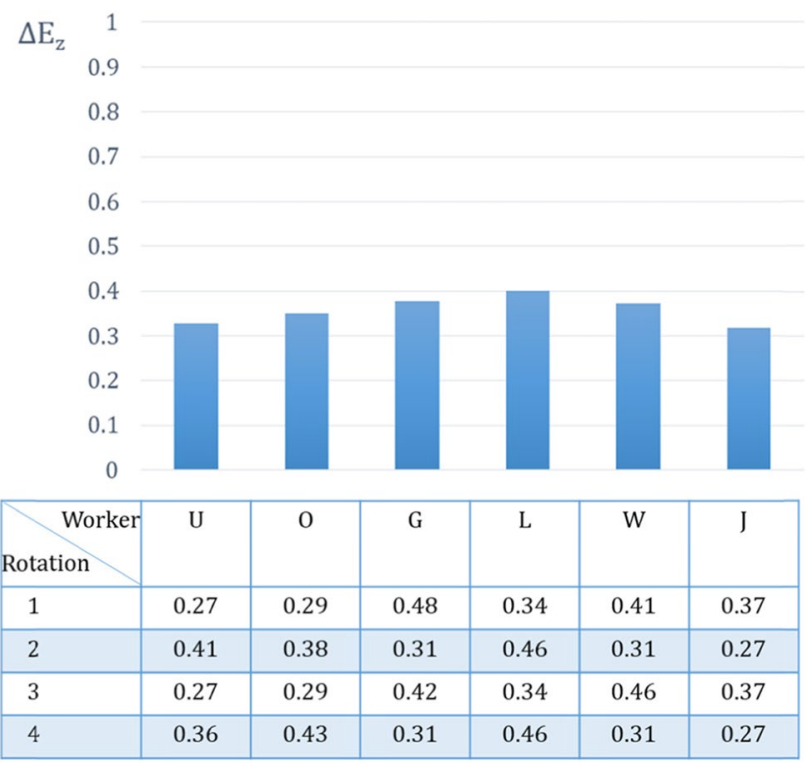

Fig. 6 Distribution of the workers' mean energy expenditure among rotations for chromosome of Fig. 5

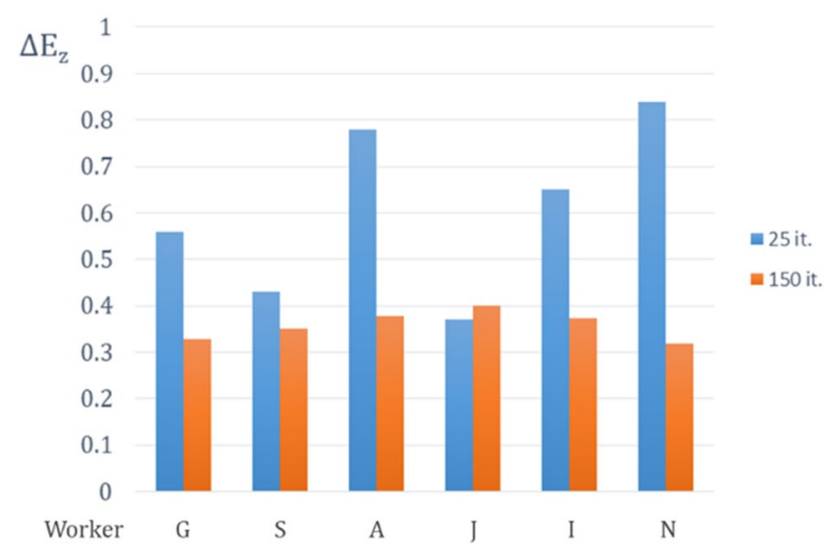

Fig. 7 Comparison on the distribution of the workers' mean energy expenditure among rotations for solutions given at iteration 25 (in blue) and at iteration 150 (in orange) (colour figure online)

with robots. These increased times may result in the cycle time to be exceeded in certain points of the assembly line, so as to justify the need for more workstations. Moreover, workers have a higher mean energy expenditure (Fig. 9) if compared with the line configuration involving HRC (Fig. 6). This is due to the support collaborative robots can give to relieve workers from an energetic overload.

Although Fig. 8 and 9 represent the best solution in terms of fitness function for the two further tested configurations, the energy load histograms may appear not so clearly balanced, mainly due to the different constraints of the problem. Nonetheless, the proposed approach is more effective in the basic scenario and demonstrates, through the computed

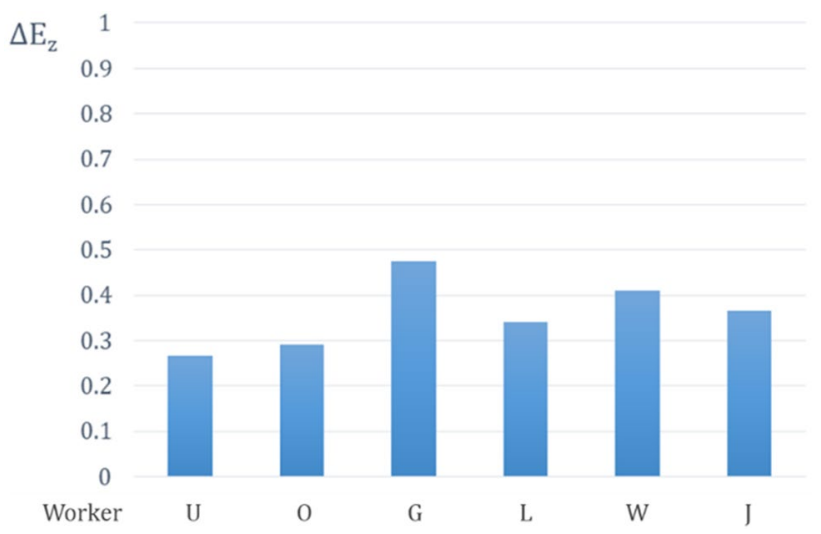

Fig. 8 Distribution of the workers' mean energy expenditure in the assembly line configuration without job rotation

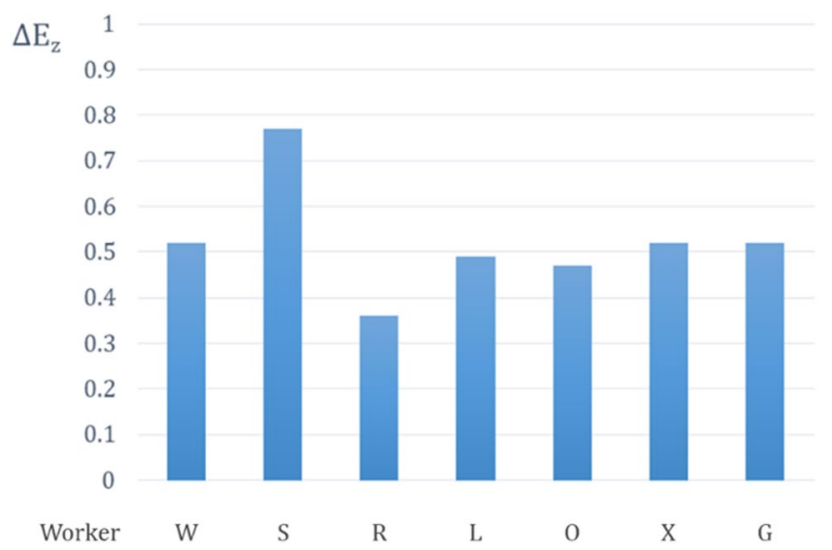

Fig. 9 Distribution of the workers' mean energy expenditure in the assembly line configuration without collaborative robots

results, to simultaneously minimize costs and energy load variance, achieving optimal compromises on the proposed objectives, thanks to the adoption of job rotation and HRC.

Therefore, the computed results show how the software tool simultaneously minimizes costs and energy load variance, achieving optimal compromises on the proposed objectives, thanks to the adoption of job rotation and HRC.

In Table 6, the characteristics of other examples and case studies tested for the validation are presented, together with the best value of the fitness reached. The results achieved highlight the versatility of the system and show its capability to deal with various problems and address different issues.

\section{Conclusions}

This paper presents a genetic algorithm-based software tool aimed at solving a novel version of the SALBP-1. The system optimizes not only production parameters, but also 
Table 6 Case studies tested

\begin{tabular}{|c|c|c|c|c|c|c|}
\hline Case & 1 & 2 & 3 & 4 & 5 & 6 \\
\hline Description & Theoretical & Lawnmower & Scooter chassis & Cylinder head & Fuel filter & $\begin{array}{l}\text { Ignition } \\
\text { distributor }\end{array}$ \\
\hline Number of components & 40 & 34 & 46 & 26 & 21 & 26 \\
\hline Number of assembly operations & 35 & 32 & 45 & 26 & 24 & 32 \\
\hline Number of movements & 190 & 223 & 225 & 133 & 127 & 144 \\
\hline Cycle time $(\min )$ & 5.00 & 6.70 & 3.80 & 1.10 & 1.30 & 0.75 \\
\hline GA population size & 100 & 150 & 200 & 150 & 250 & 100 \\
\hline GA number of iterations & 150 & 100 & 200 & 150 & 250 & 100 \\
\hline GA crossover probability & 0.98 & 0.80 & 0.90 & 0.90 & 0.95 & 0.90 \\
\hline GA mutation probability & 0.10 & 0.20 & 0.05 & 0.01 & 0.10 & 0.10 \\
\hline GA weight of objective $\alpha$ & 0.50 & 0.60 & 0.40 & 0.30 & 0.70 & 0.50 \\
\hline Best fitness value & 0.74 & 0.77 & 0.81 & 0.90 & 0.89 & 0.82 \\
\hline
\end{tabular}

ergonomics of workers, still little discussed in the scientific literature in terms of balancing the assembly line taking into account distinguishing features of workers for determining their physical capabilities. Assembly workers overloaded from an energetic point of view could undergo physical damage, also leading to medical costs and decreased process productivity. The innovative system has thus been developed to reduce the costs of implementing the assembly line and the energy load variance among workers, through to the use of job rotation and collaborative robots.

The computed results demonstrate the capability of the software tool to simultaneously minimize both objectives. Cost-efficient configurations are generated thanks to an optimal allocation of operations to workstations, whose number is minimized, according to required resources, namely, skilled workers, collaborative robots and equipment. Assembly operations needing a particular technical skill are grouped in the same workstation where the algorithm assigns a worker, from the ones at disposal for a company, having the exact skill level needed. Robots and other equipment, such as machines and tools, are allocated in a few workstations as well, where tasks requiring a particular resource are performed. Grouping operations requiring the same skill level and the same equipment allows cost-effective configurations of the assembly line. An ergonomic distribution of operations is also achieved, as demonstrated by the obtained solutions. As found in the literature, the implementation of job rotation confirms to improve ergonomics of workers. For the proposed system, experimental results show a better and smoothed distribution of energy expenditure among workers, calculated according to their personal characteristics, compared to the case of absence of job rotation. Even collaborative robots prove to enhance ergonomics, by relieving humans from heavy components handling and burdensome activities. In all tested scenarios, the tool is able to assign operations to workers not exceeding their physical capabilities and simultaneously respecting the other constraints of such a combinatorial and complex problem. This confirms its conceptual efficacy and demonstrates the context-based capability of providing the optimal solution.

Future research could be conducted with regard to other aspects improving ergonomics for workers of assembly lines, such as the reduction of perceived noise during the process. In addition, further developments of the tool could relate the extension to multi-product assembly lines and the introduction of various types of collaborative robots, differentiated by the level of dexterity.

Acknowledgements The authors wish to thank the MSc student S. Corsinovi from the University of Pisa (Italy) for his support in the experimental tests.

Author contribution Both authors MDM, GD have been responsible for planning and coordinating the steps of the research. The corresponding author MDM has been responsible for writing and reviewing the paper. GD has been responsible for revising the entire article, including structure and contents.

Funding Open access funding provided by Università di Pisa within the CRUI-CARE Agreement.

Data availability Not applicable.

Code availability Not applicable.

\section{Declarations}

Conflict of interest The authors declare no competing interests.

Ethical approval The research activity envisaged in this work has been conducted applying fundamental ethical principles. We confirm that all the authors involved in the writing of this article are aware of this 
work and approve all its contents. In addition, the paper has not been published or submitted to any other journal.

Open Access This article is licensed under a Creative Commons Attribution 4.0 International License, which permits use, sharing, adaptation, distribution and reproduction in any medium or format, as long as you give appropriate credit to the original author(s) and the source, provide a link to the Creative Commons licence, and indicate if changes were made. The images or other third party material in this article are included in the article's Creative Commons licence, unless indicated otherwise in a credit line to the material. If material is not included in the article's Creative Commons licence and your intended use is not permitted by statutory regulation or exceeds the permitted use, you will need to obtain permission directly from the copyright holder. To view a copy of this licence, visit http://creativecommons.org/licenses/by/4.0/.

\section{References}

1. Cf ODDS (2015) Transforming our world: the 2030 Agenda for Sustainable Development

2. Karwowski W (2006) The discipline of ergonomics and human factors. In: Handbook of Human Factors and Ergonomics, 3th edn., pp 3-31

3. Naeini HS, Mosaddad SH (2013) The role of ergonomics issues in engineering education. Procedia Soc Behav Sci 102:587-590

4. Golan M, Cohen Y, Singer G (2020) A framework for operator-workstation interaction in Industry 40. Int J Prod Res 58(8):2421-2432

5. Pulat BM, Alexander DC (1991) Industrial ergonomics: case studies. McGraw-Hill, New York

6. Cohen Y (2012) Absenteeism as a major cause of bottlenecks in assembly lines. Int J Prod Res 50(21):6072-6080

7. Bukchin Y, Cohen Y (2013) Minimising throughput loss in assembly lines due to absenteeism and turnover via work-sharing. Int J Prod Res 51(20):6140-6151

8. Baykasoglu A, Tasan SO, Tasan AS, Akyol SD (2017) Modeling and solving assembly line design problems by considering human factors with a real-life application. Hum Fact Ergon Manuf Serv Ind 27(2):96-115

9. Slotwinski JA, Tilove RB (2007) Smart assembly: industry needs and challenges. In: Proceedings of the 2007 Workshop on Performance Metrics for Intelligent Systems, pp 257-262

10. Michalos G, Karvouniari A, Dimitropoulos N, Togias T, Makris S (2018) Workplace analysis and design using virtual reality techniques. CIRP Ann-Manuf Technol 67(1):141-144

11. Scholl A (1999) Balancing and sequencing of assembly lines. Springer, New York

12. Sivasankaran P, Shahabudeen P (2014) Literature review of assembly line balancing problems. Int J Adv Manuf Tech 73(9-12):1665-1694

13. Otto A, Battaïa O (2017) Reducing physical ergonomic risks at assembly lines by line balancing and job rotation: a survey. Comput Ind Eng 111:467-480

14. Battini D, Faccio M, Persona A, Sgarbossa F (2011) New methodological framework to improve productivity and ergonomics in assembly system design. Int J Ind Ergon 41(1):30-42

15. Alexopoulos K, Mavrikios D, Chryssolouris G (2013) ErgoToolkit: an ergonomic analysis tool in a virtual manufacturing environment. Int J Comput Integr Manuf 26(5):440-452

16. Mavrikios D, Karabatsou V, Alexopoulos K, Pappas M, Gogos P, Chryssolouris G (2006) An approach to human motion analysis and modelling. Int J Ind Ergon 36(11):979-989
17. Pappas M, Karabatsou V, Mavrikios D, Chryssolouris G (2007) Ergonomic evaluation of virtual assembly tasks. In: Digital enterprise technology, Springer, pp 511-518

18. Caputo F, Greco A, Fera M, Macchiaroli R (2019) Digital twins to enhance the integration of ergonomics in the workplace design. Int J Ind Ergon 71:20-31

19. Moussavi SE, Zare M, Mahdjoub M, Grunder O (2019) Balancing high operator's workload through a new job rotation approach: application to an automotive assembly line. Int J Ind Ergon 71:136-144

20. Digiesi S, Facchini F, Mossa G, Mummolo G (2018) Minimizing and balancing ergonomic risk of workers of an assembly line by job rotation: a MINLP model. Int J Ind Eng Manag 9(3):129-138

21. Mossa G, Boenzi F, Digiesi S, Mummolo G, Romano VA (2016) Productivity and ergonomic risk in human based production systems: a job-rotation scheduling model. Int J Prod Econ 171:471-477

22. Michalos G, Makris S, Mourtzis D (2011) A web based tool for dynamic job rotation scheduling using multiple criteria. CIRP Ann-Manuf Technol 60(1):453-456

23. Michalos G, Makris S, Chryssolouris G (2013) The effect of job rotation during assembly on the quality of final product. CIRP J Manuf Sci Technol 6(3):187-197

24. Otto A, Scholl A (2011) Incorporating ergonomic risks into assembly line balancing. Eur J Oper Res 212(2):277-286

25. Cheshmehgaz HR, Haron H, Kazemipour F (2012) Desa MI (2012) Accumulated risk of body postures in assembly line balancing problem and modeling through a multi-criteria fuzzygenetic algorithm. Comput Ind Eng 63(2):503-512

26. Bautista J, Batalla-García C, Alfaro-Pozo R (2016) Models for assembly line balancing by temporal, spatial and ergonomic risk attributes. Eur J Oper Res 251(3):814-829

27. Barathwaj N, Raja P, Gokulraj S (2015) Optimization of assembly line balancing using genetic algorithm. J Central South Univ 22(10):3957-3969

28. Zhang Z, Tang Q, Ruiz R, Zhang L (2020) Ergonomic risk and cycle time minimization for the U-shaped worker assignment assembly line balancing problem: a multi-objective approach. Comput Oper Res 118:104905

29. Bortolini M, Faccio M, Gamberi M, Pilati F (2017) Multi-objective assembly line balancing considering component picking and ergonomic risk. Comput Ind Eng 112:348-367

30. Alghazi A, Kurz ME (2018) Mixed model line balancing with parallel stations, zoning constraints, and ergonomics. Constraints 23(1):123-153

31. Mokhtarzadeh M, Rabbani M, Manavizadeh N (2021) A novel two-stage framework for reducing ergonomic risks of a mixedmodel parallel U-shaped assembly-line. Appl Math Model 93:597-617

32. Polat O, Mutlu Ö, Özgormus E (2018) A mathematical model for assembly line balancing problem type 2 under ergonomic workload constraint. Ergon Open J 11(1):24-89

33. Akyol SD, Baykasoğlu A (2019) ErgoALWABP: a multiplerule based constructive randomized search algorithm for solving assembly line worker assignment and balancing problem under ergonomic risk factors. J Intell Manuf 30(1):291-302

34. Tiacci L, Mimmi M (2018) Integrating ergonomic risks evaluation through OCRA index and balancing/sequencing decisions for mixed model stochastic asynchronous assembly lines. Omega 78:112-138

35. Battini D, Calzavara M, Otto A, Sgarbossa F (2017) Preventing ergonomic risks with integrated planning on assembly line balancing and parts feeding. Int J Prod Res 55(24):7452-7472

36. Calzavara M, Faccio M, Persona A, Zennaro I (2021) Walking worker vs fixed worker assembly considering the impact of 
components exposure on assembly time and energy expenditure. Int J Adv Manuf Tech 112(9):2971-2988

37. Cohen Y, Shoval S, Faccio M, Minto R (2021) Deploying cobots in collaborative systems: major considerations and productivity analysis. Int J Prod Res 48:1-17

38. Pellegrinelli S, Orlandini A, Pedrocchi N, Umbrico A, Tolio T (2017) Motion planning and scheduling for human and industrialrobot collaboration. CIRP Ann-Manuf Technol 66(1):1-4

39. Wang X-V, Kemény Z, Váncza J, Wang L (2017) Human-robot collaborative assembly in cyber-physical production: classification framework and implementation. CIRP Ann-Manuf Technol 66(1):5-8

40. Mateus JC, Claeys D, Limère V, Cottyn J, Aghezzaf EH (2019) A structured methodology for the design of a human-robot collaborative assembly workplace. Int J Adv Manuf Technol 102(5):2663-2681

41. Gualtieri L, Rauch E, Vidoni R (2021) Methodology for the definition of the optimal assembly cycle and calculation of the optimized assembly cycle time in human-robot collaborative assembly. Int J Adv Manuf Tech 113(7):2369-2384

42. Cohen Y, Naseraldin H, Chaudhuri A, Pilati F (2019) Assembly systems in Industry 4.0 era: a road map to understand Assembly 4.0. Int J Adv Manuf Tech 105(9):4037-4054

43. Rabbani M, Behbahan SZB, Farrokhi-Asl H (2020) The collaboration of human-robot in mixed-model four-sided assembly line balancing problem. J Intell Robot Syst 100(1):71-81

44. Yaphiar S, Nugraha C, Ma'ruf A (2019) Mixed model assembly line balancing for human-robot shared tasks. In: Proceedings of the International Manufacturing Engineering Conference \& The Asia Pacific Conference on Manufacturing Systems, pp 245-252 Springer, Singapore

45. Boschetti G, Faccio M, Milanese M, Minto R (2021) C-ALBcollaborative assembly line balancing: a new approach in cobot solutions. J Intell Manuf 3 661-680

46. Weckenborg C, Kieckhäfer K, Müller C, Grunewald M, Spengler TS (2019) Balancing of assembly lines with collaborative robots. Bus Res 40:1-40

47. Weckenborg C, Spengler TS (2019) Assembly line balancing with collaborative robots under consideration of ergonomics: a costoriented approach. IFAC-PapersOnLine 52(13):1860-1865
48. Dalle Mura M, Dini G (2019) Designing assembly lines with humans and collaborative robots: a genetic approach. CIRP AnnManuf Technol 68(1):1-4

49. Jeon IS, Jeong BY, Jeong JH (2016) Preferred 11 different job rotation types in automotive company and their effects on productivity, quality and musculoskeletal disorders: comparison between subjective and actual scores by workers' age. Ergonomics 59(10):1318-1326

50. Diego-Mas JA, Asensio-Cuesta S, Sanchez-Romero MA, ArtachoRamirez MA (2009) A multi-criteria genetic algorithm for the generation of job rotation schedules. Int J Ind Ergon 39(1):23-33

51. Asensio-Cuesta S, Diego-Mas JA, Canós-Darós L, AndrésRomano C (2012) A genetic algorithm for the design of job rotation schedules considering ergonomic and competence criteria. Int J Adv Manuf Technol 60(9-12):1161-1174

52. Krüger J, Lien TK, Verl A (2009) Cooperation of human and machines in assembly lines. CIRP Ann-Manuf Technol 58(2):628-646

53. Cohen Y (2015) A technique for integrated modelling of manual and automatic assembly. J Manuf Technol Manag 7:28-56

54. Holland JH (1992) Genetic algorithms. Sci Am 267(1):66-73

55. Roozbazar A, Bosker GW, Richerson ME (1979) A theoretical model to estimate some ergonomic parameters from age, height and weight. Ergonomics 22(1):43-58

56. Schacherer C, Rowe A, Jackson SA (1992) Development of prediction models for physical work capacity: practical and theoretical implications. In: Proceedings of the human factors and ergonomics society annual meeting, vol 36(10), pp. 674-678 Sage Publications, Los Angeles

57. Jackson AS, Pollock ML (1978) Generalized equations for predicting body density of men. Br J Nutr 40:497-504

58. Garg A, Chaffin DB, Herrin DG (1978) Prediction of metabolic rates for manual materials handling jobs. Am Ind Hyg Assoc J 39(8):661-674

Publisher's note Springer Nature remains neutral with regard to jurisdictional claims in published maps and institutional affiliations. 